\title{
Effect of dietary supplementation with medium chain fatty acids on growth performance, intestinal histomorphology, lipid profile and intestinal microflora of broiler chickens
}

\author{
B. Baltić ${ }^{1 \#}$, J. Ćirić ${ }^{2}$, D. Šefer ${ }^{2}$, A. Radovanović ${ }^{2}$, J. Đorđević ${ }^{2}$, M. Glišić ${ }^{2}$, M. Bošković ${ }^{2}$, \\ M.Ž. Baltić ${ }^{2}$, V. Đorđević ${ }^{1} \&$ R. Marković ${ }^{2}$ \\ ${ }^{1}$ Institute of Meat Hygiene and Technology, 11000 Belgrade, Serbia \\ ${ }^{2}$ Department of Food Hygiene and Technology, Faculty of Veterinary Medicine, University of Belgrade, \\ 11000 Belgrade, Serbia
}

(Received 28 June 2018; Accepted 23 August 2018; First published online 26 December 2018)

Copyright resides with the authors in terms of the Creative Commons Attribution 4.0 South African Licence.
See: http://creativecommons.org/licenses/by/4.0/za
Condition of use: The user may copy, distribute, transmit and adapt the work, but must recognise the authors and the South African
Journal of Animal Science.

\begin{abstract}
The aim of the present study was to assess the effects of medium-chain fatty acid (MCFA) diet supplementation on growth performance, intestinal histomorphology, serum biochemistry and intestinal microflora of broiler chickens. The study was performed on 180 one-day-old broilers of the same origin (Cobb 500 hybrid), over a 42-day period. They were fed diets supplemented with three treatments: control group (basal diet without supplementation); group with MCFA supplementation; and group with MCFA and coccidiostat supplementation. Broiler chickens fed diets supplemented with MCFAs had a significantly greater final bodyweight. The weights of carcass cuts (breast, drumsticks with thighs and wings) were greater in broilers receiving MCFAs than in control broilers. The addition of MCFAs to broiler diet significantly increased villus length and crypt depth in the duodenum and caecum, and significantly decreased villus width in the duodenum and ileum. Additionally, serum HDL-cholesterol and triglyceride concentrations were increased significantly in broilers with MCFA dietary supplementation. The results indicated that the MCFA diet supplementation had a beneficial effect on the performance of broiler chickens, their intestinal histomorphology and microflora.
\end{abstract}

Keywords: Carcass characteristics, coccidiostat supplementation, nutrition, poultry, serum biochemistry \# Corresponding author: banebaltic@gmail.com

\section{Introduction}

Poultry meat is an important food resource for many people. Consumers are becoming increasingly concerned about the nutritional and health aspects of their food (Baltić et al., 2015; Janjić et al., 2015). The production of high-quality poultry meat has been a constant objective of the meat industry for many decades. The main goal is to obtain meat with high lean percentage and good meat quality traits at the same time (Baltić et al., 2011; Glamočlija et al., 2016).

Feed fats are routinely included in broiler diets as a source of essential fatty acids and energy. The use of various fats can influence broiler performance and carcass characteristics owing to differences in fatty acid chain length, degree of saturation and degree of esterification (Wang et al., 2015). Fatty acids with a chain length between 6 and 12 carbon atoms are regarded as medium-chain fatty acids (MCFAs). MCFAs are more effectively absorbed and metabolized than saturated long-chain fatty acids, and have antimicrobial properties, as shown in mammals and birds (Zentek et al., 2011). Adding MCFAs to a broiler diet to replace part of the soybean oil and animal fat has been shown to improve feed conversion efficiency (Van der Hoeven-Hangoor et al., 2013). Additionally, body fat deposition can be reduced by MCFAs (Wang et al., 2015) and breast meat yield can be enhanced (Shokrollahi et al., 2014).

Many in vitro studies have confirmed the antimicrobial properties of MCFAs against enteric pathogens (protozoa and bacteria) (Newell \& Wagenaar 2000; Bruggeman 2002; Van Immerseel et al., 2004; 
Skrivanova et al., 2005; Kabara \& Marshal 2005; Hermans et al., 2011). To consider such antibacterial properties, MCFAs, such as new non-antibiotic feed additives, are helpful in bolstering healthy gastrointestinal conditions in broilers. Based on research with poultry, MCFAs can be an alternative to antibiotic growth promoters. Aromabiotic is a commercial product, which contains a mixture of MCFAs that demonstrate antimicrobial, physiological and immunological properties (Isaac et al., 2013). It was reported that Aromabiotic decreased the invasion of enteric pathogens, decreased mortality and had positive effects on growth performance and intestinal histomorphology in broiler chickens (Khosravinia, 2015; Gutierrez et al., 2006) and Japanese quail (Saeidi et al., 2016). Numerous natural products, such as sources of fats containing high concentrations of n-3 fatty acids or feedstuffs, have been tested as anticoccidial dietary additives (Tan \& Long, 2012). MCFAs have been found to have anticoccidial activity in calves and antiprotozoal activity in dairy cattle, swine, sheep, goat and infant animals (Tan \& Long, 2012).

The objective of this study was to evaluate the effect of dietary supplementation with MCFAs on growth performance, intestinal histomorphology and microbiota and serum biochemistry of broiler chickens, for 42 days.

\section{Materials and Methods}

The experimental protocol was approved by the Veterinary Directorate of the Serbian Ministry of Agriculture, Forestry and Water Management and the Ethics Committee of the Faculty of Veterinary Medicine, University of Belgrade.

A total of 180 one-day-old broilers of both sexes and the same origin (Cobb 500) were used in this study in a 42-day period. Birds were randomly assigned to one of three dietary treatments (control and two experimental groups), each having 6 replicates (10 birds in each replicate). Birds were placed in an environmentally controlled room (stocking density 6 birds $/ \mathrm{m}^{2}$ ) with $5 \mathrm{~cm}$ thick sawdust. The temperature in the room was $32{ }^{\circ} \mathrm{C}$ from days 1 to 5 , then gradually lowered to $22^{\circ} \mathrm{C}$ on day 21 . This temperature was maintained until the end of the study. Relative humidity was $45 \%-50 \%$. The lighting of the rooms was 24 hours. Water and feed were supplied ad libitum throughout the study.

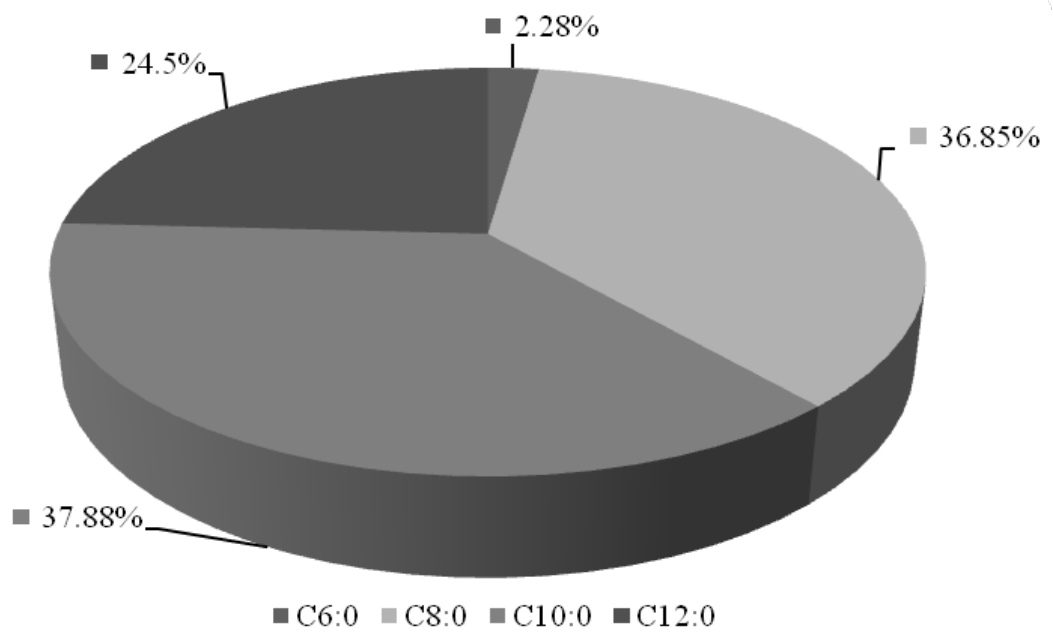

Figure 1 Fatty acid composition* of Aromabiotic $^{R}$

*Total lipids for fatty acid determination were extracted from Aromabiotic with hexane/isopropanol mixture by accelerated solvent extraction (ASE 200, Dionex, Germany). After evaporation of solvent until dryness under the stream of nitrogen, total lipids were converted to fatty acid methyl esters (FAME) by trimethylsulfonium hydroxide. FAMEs were determined with a Shimadzu 2010 gas chromatograph equipped with flame ionization detector (FID) and cianopropyl HP-88 capillary column (100 m x $0.25 \mathrm{~mm} \times 0.20 \mu \mathrm{m})$ (Trbović et al., 2011).

From the start of the trial, each group of broilers was fed with one of three experimental diets, which comprised the same basal diet, and differed only in additive supplementation (MCFAs or coccidiostat). The basal diet was formulated to meet the maintenance and growth requirements of the animals used in the study. Broilers were fed from day 1 to day 42 in three phases with three nutritionally different concentrated feed mixtures, namely starter (up to 10 days), grower ( $11-21$ days) and finisher ( $22-42$ days) mixtures. The broilers in the control group were given a diet without MCFAs or coccidiostat (C group). The other two treatment groups were given the same diet as the control group (C group), but were supplemented with 
MCFAs (Aromabiotic ${ }^{R}$, Nuscience, Belgium) (E-I group) and MCFAs (Aromabiotic) with coccidiostat (salinomycin, $500 \mathrm{mg} / \mathrm{t}$ feed, 1 - 35 days) (E-II group). Commercially prepared MCFAs (60\%) (Aromabiotic) was added to the feed (starter: $0.16 \%$, grower: $0.12 \%$ and finisher: $0.10 \%)$ for the experimental groups (E-I and $\mathrm{E}-\mathrm{II}$ ), at the producer-recommended rate in the feed mixture. The fatty acid composition of Aromabiotic is shown in Figure 1. 1.

The ingredients and chemical composition (calculated analyses) of the basal diets are listed in Table

Table 1 Formulation and calculated values of the feed mixtures for broilers

\begin{tabular}{|c|c|c|c|c|c|c|}
\hline \multirow{2}{*}{ Ingredients (\%) } & \multicolumn{2}{|c|}{ Starter (up to 10 days) } & \multicolumn{2}{|c|}{ Grower (days 11-21) } & \multicolumn{2}{|c|}{ Finisher (days 22-42) } \\
\hline & $\begin{array}{c}C^{*} \\
\text { group }\end{array}$ & $\begin{array}{c}\mathrm{E}-\mathrm{I} \text { and } \mathrm{E}-\mathrm{II}^{*} \\
\text { groups }\end{array}$ & $\begin{array}{c}\text { C } \\
\text { group }\end{array}$ & $\begin{array}{l}\text { E-I and E-II } \\
\text { groups }\end{array}$ & $\begin{array}{c}\text { C } \\
\text { group }\end{array}$ & $\begin{array}{c}\text { E-I and E-II } \\
\text { groups }\end{array}$ \\
\hline Maize & 50.85 & 50.69 & 44.15 & 44.03 & 44.95 & 44.85 \\
\hline Wheat & - & - & 10.00 & 10.00 & 15.00 & 15.00 \\
\hline Soy grits & 15.00 & 15.00 & 17.00 & 17.00 & 20.00 & 20.00 \\
\hline Soybean meal & 12.40 & 12.40 & 1.00 & 1.00 & 1.00 & 1.00 \\
\hline Soybean cake & 17.00 & 17.00 & 23.30 & 23.30 & 14.70 & 14.70 \\
\hline Monocalcium phosphate & 1.20 & 1.20 & 1.00 & 1.00 & 0.90 & 0.90 \\
\hline Chalk & 1.60 & 1.60 & 1.60 & 1.60 & 1.60 & 1.60 \\
\hline Salt & 0.35 & 0.35 & 0.35 & 0.35 & 0.35 & 0.35 \\
\hline Premix $x^{\star *}$ & 1.00 & 1.00 & 1.00 & 1.00 & 1.00 & 1.00 \\
\hline Lysine & 0.20 & 0.20 & 0.20 & 0.20 & 0.10 & 0.10 \\
\hline Methionine & 0.20 & 0.20 & 0.20 & 0.20 & 0.20 & 0.20 \\
\hline Adsorbent & 0.20 & 0.20 & 0.20 & 0.20 & 0.20 & 0.20 \\
\hline Aromabiotic & - & 0.16 & - & 0.12 & - & 0.10 \\
\hline Parameter & \multicolumn{6}{|c|}{ Calculated values } \\
\hline Metabolic energy MJ/kg & 12.69 & 12.71 & 13.01 & 13.03 & 13.11 & 13.13 \\
\hline Total ash & 6.77 & 6.77 & 6.66 & 6.66 & 6.16 & 6.15 \\
\hline Total lipids & 6.61 & 6.76 & 7.39 & 7.51 & 7.20 & 7.29 \\
\hline Crude fibre & 3.89 & 3.89 & 3.97 & 3.97 & 3.44 & 3.44 \\
\hline Crude protein & 22.24 & 22.22 & 21.14 & 21.13 & 19.62 & 19.62 \\
\hline Moisture & 10.41 & 10.39 & 10.20 & 10.18 & 10.54 & 10.53 \\
\hline Lysine & 1.50 & 1.49 & 1.42 & 1.42 & 1.17 & 1.17 \\
\hline Methionine+ cysteine & 0.81 & 0.81 & 0.80 & 0.80 & 0.76 & 0.76 \\
\hline Tryptophan & 0.31 & 0.31 & 0.29 & 0.29 & 0.27 & 0.27 \\
\hline Calcium & 1.01 & 1.01 & 0.94 & 0.94 & 0.90 & 0.90 \\
\hline Phosphorus & 0.59 & 0.59 & 0.56 & 0.56 & 0.54 & 0.54 \\
\hline NFE & 50.08 & 49.96 & 50.63 & 50.55 & 53.04 & 52.97 \\
\hline
\end{tabular}

${ }^{*}$ Control group (no supplementation); E-I: broilers supplemented with medium chain fatty acids; E-II: broilers supplemented with medium chain fatty acids and coccidiostat

**Mineral-vitamin premix provided per kg of diet: vitamin A, $12999 \mathrm{IU}$; vitamin D3, $4950 \mathrm{IU}$; vitamin E, $75 \mathrm{mg}$; vitamin $\mathrm{K}_{3}$, $3 \mathrm{mg}$; vitamin $B_{1}, 3 \mathrm{mg}$; vitamin $B_{2}, 7.95 \mathrm{mg}$; vitamin $B_{6}, 4.05 \mathrm{mg}$; vitamin $B_{12}, 0.0195 \mathrm{mg}$; vitamin $C, 19.95 \mathrm{mg}$; biotin, $0.15 \mathrm{mg}$; niacin, $60 \mathrm{mg}$; calcium pantothenate $15 \mathrm{mg}$; folic acid, $1.95 \mathrm{mg}$; iodine, $1.0005 \mathrm{mg}$ selenium, $0.3 \mathrm{mg}$; choline chloride, 399.9 mg; iron, 39.99 mg; copper, 15 mg; manganese, 99.9 mg; zinc, 99.9 mg; methionine, 2100 mg; lysine, $1200 \mathrm{mg}$

NFE: nitrogen free extract

Growth performance of broilers was evaluated by recording bodyweight gain, feed intake and feed conversion ratio (FCR) during the 42-day experimental period. Feed intakes of birds were recorded on a pen 
basis, the uneaten feed was discarded, and fresh feed was placed in feeders at the end of each day. FCR was calculated as the amount of feed consumed per unit of bodyweight gain.

At the end of the study, animals were transported to a slaughterhouse and then weighed individually, stunned electrically and immediately slaughtered by severing the jugular veins. Subsequently, animals were processed following standard industrial techniques and hot carcass weight was recorded. After evisceration, liver weights were measured. During the first 24 hours post mortem, carcasses were stored in a ventilated cold room at $2{ }^{\circ} \mathrm{C}$, after which cold carcass weight was measured. After chilling, the carcasses of broilers from each group were separated into breast, drumsticks with thighs, wings, neck and back with pelvis. The various carcass parts were weighed.

For morphological and histological analyses, tissue samples from the duodenum, ileum and caecum were collected from the slaughtered birds and fixed in $10 \%$ buffered formalin saline. Tissues were dehydrated by immersing through a series of alcohols of increasing concentrations (from $70 \%$ to absolute), infiltrated with xylene, and embedded in paraffin. A rotary type microtome was used for cutting the paraffin sections. Sections 5 to $8 \mu \mathrm{m}$ in thickness were cut and stained with Mayer's haematoxylin and eosin (HE) and with a combination of periodic acid Schiff stain and Alcian blue (PAS-AB) (Yamabayashi 1987; Smirnov et al., 2005). Analysis was performed using a light microscope (Olympus BX53) with the objective magnifications $\times 4$ and $\times 10$. Morphometric examinations were carried out using Olympus cellSens software (http://www.olympusamerica.com) and included these measurements: ileal villi height and width, ileal crypt depth and caecal crypt depth (Bergamo et al., 2016).

The $\mathrm{pH}$ of various segments of the digestive tract was determined with a digital $\mathrm{pH}$ meter (TESTO 205, Germany).

Blood samples were collected from the slaughtered birds in non-heparinized tubes. The samples were centrifuged at $3000 \mathrm{rpm}$ for 15 minutes, and the serum was stored at $-20^{\circ} \mathrm{C}$ until analysis. HDL-cholesterol and triglyceride were determined by the auto analyser (CentroLIA LB 961, Berthold Technologies, Germany) using commercial kits from Accurex biomedical company.

Samples for bacteriological examination were taken directly from the intestines with a sterile syringe. Serial dilutions were prepared down to $10^{-8}$. Duplicate plates of selective media were inoculated with $0.1 \mathrm{~mL}$ of each dilution to determine the bacterial species defined by standard laboratory methods. Total Enterococcus species, Escherichia coli strains and Staphylococcus aureus were counted on UTI agar (urogenital tract infections agar) (HiMedia) after incubation for 24 hours at $37^{\circ} \mathrm{C}$, while lactic acid bacteria (LAB) counts were determined on selective MRS agar (de Man, Rogosa and Sharpe) agar supplemented with $20 \mathrm{mg} / \mathrm{mL}$ vancomycin (Sigma Aldrich) and $2 \mathrm{mg} / \mathrm{mL}$ cefotaxime (Sigma Aldrich), after incubation for 72 hours at $30{ }^{\circ} \mathrm{C}$. Microaerophilic atmospheres, used for the growth of lactobacilli on agar plates, were obtained using the Anaerocult ${ }^{R} \mathrm{C}$ (Merck KgaA, Darmstadt, Germany). Based on the appearance of colonies and cultural characteristics, subcultivation was performed on suitable substrates to obtain pure bacterial cultures. After cultivation, morphological and biochemical characterization of the isolated bacteria were conducted.

Statistical analysis of the results was conducted with GraphPad Prism software version 6.00 for Windows (GraphPad Software, San Diego, CA, USA, www.graphpad.com). All parameters were described by means and standard error of means (SEM). One-way ANOVA with Tukey's post hoc test was performed to assess the significance of differences among control and experimental groups. Values of $P<0.05$ were considered significant.

\section{Results}

Table 2 shows growth performance and carcass characteristics of broilers in the study. At the end of the study, significant $(P<0.05)$ differences in weight gain and final bodyweight were found between control and experimental groups receiving diets containing MCFAs and coccidiostat. Feed intake for the overall period of the study was lower in the control group than in the group with MCFAs (E-I group) added to feed and in the group with MCFAs and coccidiostat added to feed (E-II group) $(P>0.05)$. Broilers fed only with the basal diet showed a higher FCR (from day 0 to day 42) than E-I group and E-II group.

The cold carcass weight was significantly lower in the control group than in the E-I and E-II groups. Dressing percentage was lower in the control group compared with the other groups. Basic cuts of broiler carcasses (breast, drumsticks with thighs, wings, neck and back with pelvis), presented as weight and calculated percentage of carcass, differed significantly among the broiler groups. Supplementation of MCFAs significantly improved the yield of carcass cuts, in which the control group had lower $(P<0.05)$ weight of breast, drumsticks with thighs and wings compared with the other experimental groups. 
Table 2 Performance and carcass characteristics of broilers receiving diets containing medium chain fatty acids and coccidiostat

\begin{tabular}{|c|c|c|c|c|c|}
\hline \multirow{2}{*}{ Parameter } & \multicolumn{3}{|c|}{ Group } & \multirow{2}{*}{ SEM } & \multirow{2}{*}{$P$-value } \\
\hline & C & E-I & E-II & & \\
\hline \multicolumn{6}{|l|}{ Body weight (g) } \\
\hline Day 1 & 41.96 & 42.06 & 42.13 & 0.79 & 0.963 \\
\hline Day 10 & 306.0 & 313.2 & 308.6 & 5.34 & 0.251 \\
\hline Day 21 & $876.5^{a}$ & $939.8^{b}$ & $937.3^{b}$ & 30.51 & 0.045 \\
\hline Day 42 & $2358^{\mathrm{a}}$ & $2520^{b}$ & $2510^{b}$ & 53.37 & 0.0003 \\
\hline \multicolumn{6}{|l|}{ Feed intake (g) } \\
\hline Day $1-10$ & 345.4 & 343.4 & 341.0 & 2.60 & 0.153 \\
\hline Day 1-21 & $125^{a}$ & $128^{b}$ & $128^{\mathrm{b}}$ & 9.24 & 0.0012 \\
\hline Day 1-42 & 4343 & 4361 & 4356 & 29.58 & 0.740 \\
\hline \multicolumn{6}{|l|}{ Weight gain (g) } \\
\hline Day 1-10 & 264.0 & 271.1 & 266.5 & 4.59 & 0.161 \\
\hline Day 1-21 & $834.5^{a}$ & $897.8^{b}$ & $895.2^{b}$ & 29.74 & 0.014 \\
\hline Day $1-42$ & $2316^{a}$ & $2478^{b}$ & $2468^{b}$ & 52.65 & 0.0002 \\
\hline \multicolumn{6}{|l|}{ Feed conversion ratio } \\
\hline Day 1-10 & $1.31^{\mathrm{a}}$ & $1.27^{\mathrm{b}}$ & $1.28^{\mathrm{b}}$ & 0.01 & 0.0004 \\
\hline Day 1-21 & $1.51^{\mathrm{a}}$ & $1.43^{\mathrm{b}}$ & $1.44^{b}$ & 0.0095 & $<0.0001$ \\
\hline Day 1-42 & $1.88^{\mathrm{a}}$ & $1.76^{\mathrm{b}}$ & $1.77^{\mathrm{b}}$ & 0.0122 & $<0.0001$ \\
\hline Dressing percentage (\%) & $73.14^{\mathrm{a}}$ & $74.94^{\mathrm{b}}$ & $74.05^{a, b}$ & 0.49 & $<0.0001$ \\
\hline CCW (g) & $1724^{\mathrm{a}}$ & $1889^{b}$ & $1858^{\mathrm{b}}$ & 40.37 & $<0.0001$ \\
\hline Liver weight (g) & 42.28 & 46.76 & 46.56 & 1.66 & 0.046 \\
\hline \multicolumn{6}{|l|}{ Carcass cuts weight (g) } \\
\hline Breast & $665.0^{\mathrm{a}}$ & $734.0^{b}$ & $738.5^{b}$ & 16.78 & $<0.0001$ \\
\hline Drumsticks with thighs & $487.9^{\mathrm{a}}$ & $545.5^{\mathrm{b}}$ & $543.8^{\mathrm{b}}$ & 15.03 & $<0.0001$ \\
\hline Wings & $163.9^{\mathrm{a}}$ & $175.8^{\mathrm{b}}$ & $170.7^{b}$ & 2.93 & $<0.0001$ \\
\hline Neck & $83.25^{\mathrm{a}}$ & $88.98^{\mathrm{b}}$ & $80.78^{\mathrm{a}}$ & 1.78 & $<0.0001$ \\
\hline Back with pelvis & $325.0^{\mathrm{a}}$ & $338.6^{a}$ & $307.8^{\mathrm{b}}$ & 7.92 & $<0.0001$ \\
\hline \multicolumn{6}{|c|}{ Carcass cuts percentage (\%) } \\
\hline Breast & $38.55^{\mathrm{a}}$ & $39.00^{\mathrm{a}}$ & $40.05^{b}$ & 0.25 & $<0.0001$ \\
\hline Drumsticks with thighs & $28.25^{\mathrm{a}}$ & $28.94^{\mathrm{b}}$ & $29.44^{b}$ & 0.33 & 0.0001 \\
\hline Wings & 9.56 & 9.35 & 9.33 & 0.16 & 0.145 \\
\hline Neck & $4.83^{\mathrm{a}}$ & $4.74^{\mathrm{a}}$ & $4.41^{b}$ & 0.07 & $<0.0001$ \\
\hline Back with pelvis & $18.80^{\mathrm{a}}$ & $17.98^{\mathrm{b}}$ & $16.77^{\mathrm{c}}$ & 0.20 & $<0.0001$ \\
\hline
\end{tabular}

Data are means and SEM ( $\mathrm{n}=60$ per group). CCW: cold carcass weight

Within a row, means with different lowercase superscript letters $(P<0.05)$ are significantly different

Control group (no supplementation); E-I: broilers supplemented with medium chain fatty acids; E-II: broilers supplemented with medium chain fatty acids and coccidiostat

The effects of MCFA and coccidiostat on intestinal morphometric parameters expressed as means of crypt depth, villus width and villus length for all groups are shown in Table 3. Some typical photomicrographs are shown in Figure 2. In this study, the inclusion of MCFAs in the diet increased the duodenal villus length $(P<0.05)$. A numerically but not statistically significant increase in crypt depth was observed in the E-II group compared with control and E-I. The dietary treatment affected the villus length/depth ratio $(P<0.05)$ of duodenum, as this was greater in both experimental groups (Table 3). 
Table 3 Intestinal morphometric parameters of broiler chickens

\begin{tabular}{|c|c|c|c|c|c|}
\hline \multirow{2}{*}{ Parameters } & \multicolumn{3}{|c|}{ Groups } & \multirow{2}{*}{ SEM } & \multirow{2}{*}{$P$-value } \\
\hline & C & E-I & E-II & & \\
\hline \multicolumn{6}{|l|}{ Duodenum $(\mu \mathrm{m})$} \\
\hline Crypt depth & 177.0 & 177.4 & 179.7 & 4.867 & 0.704 \\
\hline Villus width & $64.47^{\mathrm{a}}$ & $59.48^{\mathrm{b}}$ & $63.35^{\mathrm{a}}$ & 2.047 & 0.001 \\
\hline Villus length & $472.9^{\mathrm{a}}$ & $875.4^{b}$ & $705.9^{c}$ & 28.901 & $<0.0001$ \\
\hline \multicolumn{6}{|l|}{ Ileum ( $\mu \mathrm{m})$} \\
\hline Crypt depth & $223.3^{\mathrm{a}}$ & $163.9^{\mathrm{b}}$ & $164.3^{\mathrm{b}}$ & 6.107 & $<0.0001$ \\
\hline Villus width & $74.92^{\mathrm{a}}$ & $55.42^{b}$ & $65.36^{c}$ & 2.195 & $<0.0001$ \\
\hline Villus length & $503.8^{\mathrm{a}}$ & $267.4^{\mathrm{b}}$ & $331.2^{c}$ & 19.14 & $<0.0001$ \\
\hline \multicolumn{6}{|l|}{ Caecum $(\mu \mathrm{m})$} \\
\hline Crypt depth & 168.3 & 173.0 & 173.9 & 4.870 & 0.173 \\
\hline Villus width & 58.95 & 58.42 & 58.15 & 1.856 & 0.801 \\
\hline Villus length & $201.7^{\mathrm{a}}$ & $219.7^{b}$ & $236.0^{c}$ & 6.372 & $<0.0001$ \\
\hline \multicolumn{6}{|c|}{ Villus length I depth ratio } \\
\hline Duodenum & $3.26^{\mathrm{a}}$ & $5.01^{b}$ & $3.99^{c}$ & 0.208 & $<0.0001$ \\
\hline Ileum & $2.34^{\mathrm{a}}$ & $1.67^{\mathrm{b}}$ & $0.13^{\mathrm{c}}$ & 0.122 & $<0.0001$ \\
\hline Caecum & $1.22^{\mathrm{a}}$ & $1.27^{\mathrm{b}}$ & $2.03^{\mathrm{c}}$ & 0.050 & $<0.0001$ \\
\hline
\end{tabular}

Data are means and SEM

Within a row, means with different lower-case superscript letters $(P<0.05)$ are significantly different

Control group (no supplementation); E-I: broilers supplemented with medium chain fatty acids; E-II: broilers supplemented with medium chain fatty acids and coccidiostat
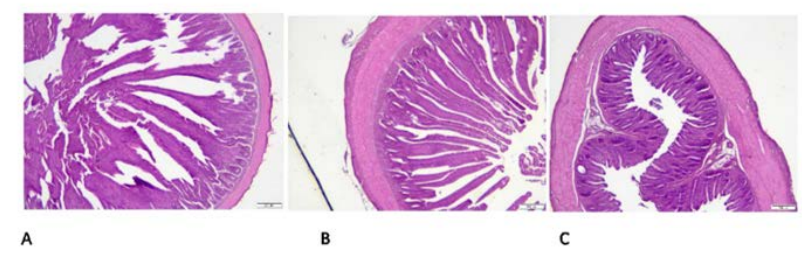

c

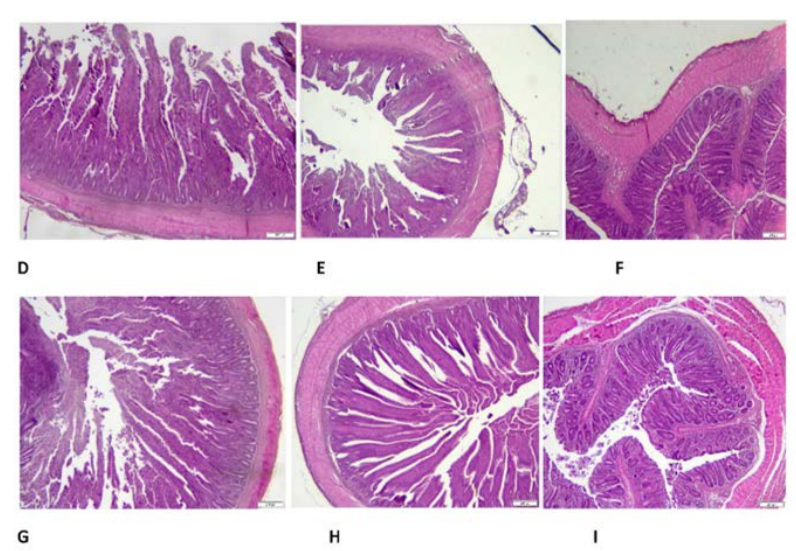

Figure 2 Photomicrographs of intestinal segments in control group and E-I and E-II groups

Histomorphology of the duodenum (A), ileum (B) and caecum (C) of broiler chicken in control group. Histomorphology of the duodenum (D), ileum (E) and caecum (F) of broiler chicken in E-I group (broilers supplemented with medium chain fatty acids). Histomorphology of the duodenum (G), ileum $(\mathrm{H})$ and caecum (I) of broiler chicken in E-II group (broilers supplemented with medium chain fatty acids and coccidiostat. Haematoxylin and eosin staining. Scale bars represent $200 \mu \mathrm{m}$ 
The ileal villus crypt depth was significantly decreased in broilers with MCFA and coccidiostat supplementation compared with the control group $(P<0.05)$. Moreover, MCFA supplementation decreased the villus width and villus length $(P<0.05)$ compared with the other groups $(P<0.05)$. Furthermore, coccidiostat supplementation decreased the ileal villus length/depth ratio significantly $(P<0.05)$. In the caecum, the crypt depth of E-II group was numerically, but not statistically significantly greater than it was in control and E-I group (Table 3). Supplementation with MCFAs and coccidiostat (E-II group) significantly increased $(P<0.05)$ villus length in caecum. Also, the combination of MCFAs and coccidiostat significantly increased $(P<0.05)$ the villus length/depth ratio.

Feed with MCFAs and coccidiostat resulted in increased $\mathrm{pH}$ of the duodenum $(P<0.05)($ Table 4). The $\mathrm{pH}$ of the ileum did not change markedly when MCFAs and coccidiostat were supplemented in the diet, although the $\mathrm{pH}$ tended to decrease when diet was supplemented with MCFAs only. In the caecum, the $\mathrm{pH}$ was significantly decreased $(P<0.05)$ in $\mathrm{E}-\mathrm{I}$ group compared to that in the control and E-II group.

Table $4 \mathrm{pH}$ in various segments of broiler gastrointestinal tract

\begin{tabular}{lccccc}
\hline \multirow{2}{*}{ Parameters } & \multicolumn{3}{c}{ Groups } & SEM & P-value \\
\cline { 2 - 4 } & C & E-I & E-II & & 0.225 \\
Duodenum & $5.88^{\mathrm{a}}$ & $5.97^{\mathrm{ab}}$ & $6.02^{\mathrm{b}}$ & 0.031 & 0.5470 \\
Ileum & 5.65 & 5.52 & 5.68 & 0.061 & 0.0006 \\
Caecum & $6.40^{\mathrm{a}}$ & $5.77^{\mathrm{b}}$ & $6.14^{\mathrm{a}}$ & 0.048 &
\end{tabular}

Data are means and SEM. Within a row, means with different lower-case superscript $(P<0.05)$ letters are significantly different. Control group (no supplementation); E-I: broilers supplemented with medium chain fatty acids; E-II: broilers supplemented with medium chain fatty acids and coccidiostat

The mean values of serum biochemistry parameters (HDL-cholesterol and triglyceride) of broiler chickens fed MCFA-supplemented diets are shown in Table 5. Supplementation of MCFAs or MCFAs and coccidiostat produced no significant differences $(P>0.05)$ in the mean concentration of HDL-cholesterol in the broilers' sera. There was a significant increase $(P<0.05)$ in the triglyceride levels in the broilers fed diets supplemented with MCFAs compared with the control group.

Table 5 Lipid profile of broiler chickens

\begin{tabular}{lcccccc}
\hline \multirow{2}{*}{ Parameters (mmol/L) } & \multicolumn{3}{c}{ Groups } & & \multirow{2}{*}{ SEM } & P-value \\
\cline { 2 - 4 } & C & E-I & E-II & & \\
HDL-cholesterol & 2.71 & 3.01 & 2.69 & 0.053 & 0.05 \\
Triglyceride & $0.60^{\mathrm{a}}$ & $0.78^{\mathrm{b}}$ & $0.70^{\mathrm{ab}}$ & 0.017 & 0.002 \\
\hline
\end{tabular}

Data are means and SEM

Within a row, means with different lowercase $(P<0.05)$ letters are significantly different. Control group (no supplementation); E-I: broilers supplemented with medium chain fatty acids; E-II: broilers supplemented with medium chain fatty acids and coccidiostat

The results of microbial community analyses in the various segments of the intestinal tract are presented in Table 6. The highest counts were measured in the caecum. None of the dietary treatments affected the $E$. coli or $S$. aureus counts in the ileum or caecum. Enterococcus spp. and LAB counts, on the other hand, were significantly $(P<0.05)$ influenced by both dietary treatments, except Enterococcus spp. counts in caecum, where no significant differences were detected. The lowest LAB and Enterococcus spp. counts were observed in the ileum of broilers fed E-I, while in the caecum, the lowest LAB count was in E-II group fed diet with MCFAs and coccidiostat. In duodenum, the lowest numbers of all bacterial groups were observed in control broilers, except $S$. aureus count which was the lowest in E-I broilers. 
Table 6 Effect of Aromabiotic and salinomycin on microbiota in various intestinal segments of broilers

\begin{tabular}{lccccc}
\hline & \multicolumn{3}{c}{ Groups } & SEM & P-value \\
\cline { 2 - 3 } & C & E-I & E-II & & \\
\hline Duodenum (log CFU/g) & & & & \\
\hline LAB & $3.65^{\mathrm{a}}$ & $3.90^{\mathrm{a}}$ & $4.69^{\mathrm{b}}$ & 0.24 & 0.0002 \\
Enterococcus spp. & $3.30^{\mathrm{a}}$ & $3.57^{\mathrm{b}}$ & $3.54^{\mathrm{b}}$ & 0.03 & $<0.0001$ \\
E. coli & $3.31^{\mathrm{a}}$ & $3.54^{\mathrm{b}}$ & $3.48^{\mathrm{ab}}$ & 0.08 & 0.0093 \\
Staphylococcus aureus & $4.15^{\mathrm{a}}$ & $3.80^{\mathrm{b}}$ & $4.19^{\mathrm{a}}$ & 0.16 & 0.0181 \\
\hline Ileum (log CFU/g) & & & & & 0.0019 \\
\hline LAB & $4.47^{\mathrm{a}}$ & $3.68^{\mathrm{b}}$ & $4.14^{\mathrm{ab}}$ & 0.22 & $<0.0001$ \\
Enterococcus spp. & $3.80^{\mathrm{a}}$ & $3.65^{\mathrm{a}}$ & $4.17^{\mathrm{b}}$ & 0.08 & 0.1012 \\
E. coli & 3.78 & 3.74 & 4.05 & 0.18 & 0.0753 \\
Staphylococcus aureus & 4.68 & 4.34 & 4.34 & 0.19 & \\
\hline Caecum (log CFU/g) & & & & & 0.0001 \\
\hline LAB & $7.14^{\mathrm{a}}$ & $6.33^{\mathrm{b}}$ & $5.71^{\mathrm{b}}$ & 0.29 & 0.5642 \\
Enterococcus spp. & 6.33 & 6.15 & 6.53 & 0.43 & 0.7303 \\
E. coli & 6.28 & 6.00 & 6.22 & 0.44 & 0.0786 \\
Staphylococcus aureus & 5.36 & 5.21 & 4.80 & & \\
\hline
\end{tabular}

Within a row, means with different lowercase $(P<0.05)$ letters are significantly different

Control group (no supplementation); E-I: broilers supplemented with medium chain fatty acids; E-II: broilers supplemented with medium chain fatty acids and coccidiostat

LAB: lactic acid bacteria

\section{Discussion}

Numerous studies have suggested that the effectiveness of MCFAs on growth stimulation of birds would produce a final result of improved gastrointestinal ecosystem, with ensuing augmented intestinal environment, integrity of the intestinal mucosal barrier, digestive and immune function of intestine and broiler health (Tellez et al., 2006; Mountzouris et al., 2010; Hayat et al., 2014). The results of this study indicate that broiler performance was affected positively by adding MCFAs to the broiler diets. There are relatively few literature data on the effect of MCFAs on broiler production. De Los Santos et al. (2008) found that supplementation with 1.4\% caprylic acid (an 8-carbon MCFA) in a regular chick starter diet reduced feed consumption. This result is similar to those of the present study. The effect of MCFAs has been studied extensively in other animals. Miller et al. (2009) reported that no differences occurred with regard to feed intake, feed efficiency and weight gain in grower and finisher pigs when fed diets with $1 \%, 3 \%$ and $6 \%$ MCFA oil compared with diets containing the same amount of tallow, pig fat or corn oil. However, these results are at variance with those of Dove (1993), who showed that dietary inclusion of 5\% MCFAs provided the greatest increase in weight gain and a better feed conversion for post-weaning piglets compared with other sources of fat (soybean oil and animal fat). Bodyweight gain and feed intake of White Leghorn chicks decreased with diets containing 10\% MCFA oil (Furuse et al., 1992).

The beneficial effect of MCFA supplementation in broiler diets in terms of increased final bodyweight and FCR is documented in studies from several research groups (O'Dea et al., 2006; Timmerman et al., 2006; Onderci et al., 2008; Bansal et al., 2011). This was also the case in the present study, at 42 days, even though there was no difference in feed consumption between broilers fed diet supplemented with MCFAs and the broilers in our control group. The improvement in live bodyweight at the end of the growth phase due to the supplementation of MCFAs was presumed to be a result of bacterial antagonism, competition for colonization site, competition for nutrients, a reduction in toxic compounds or modulation of immune system (Applegate et al., 2010). In the present study, the broilers supplemented with MCFAs and coccidiostat had a significantly higher hot carcass weight compared with broilers from the control group. The MCFAs in diets had a marked positive effect on some carcass cuts (breast, drumsticks with thighs and wings), as these weighed significantly more in broilers fed MCFA-treated diets than in broilers fed only basal diet. Conversely, other studies showed no broiler performance improvement when birds received MCFAs in comparison with control birds and birds fed antibiotics (Gunal et al., 2006; Vieira et al., 2008). However, at 
the moment, numerous studies suggest that MCFAs have growth-promoting properties and can be used as alternatives to antibiotics and anticoccidiostats (Tan \& Long, 2012; Khan \& Iqbal, 2016).

In the current study, the positive response of broiler growth performance in final bodyweight as a result of inclusion of MCFAs in the diet might partly be explained by intestinal histological changes and villus characteristics.

Good intestinal health in the poultry industry is of great importance in achieving target growth rates and feed efficiency. MCFA supplementation significantly increased the villus width, height and area of the duodenum, jejunum and ileum of broiler chicks at 14 days old (Garclá et al., 2007; Kum et al., 2010; Rodríguez-Lecompte et al., 2012; Sultan et al., 2015; Abudabos et al., 2017). Thus, MCFA supplementation increased both the villus height and crypt depth. Leeson et al. (2005) and Panda et al. (2009) reported that MCFAs in broilers' diet improved the villus length and crypt depth in the duodenum, so concluded this supplementation could be highly helpful to young birds for intestinal development. In another study, the highest duodenal and ileal villus heights were recorded in birds fed diets supplemented with MCFAs (Adil et al., 2010).

In the current study, broilers fed MCFA-supplemented diets had increased duodenum villus length. Increases of villus length could cause greater enzyme production and better digestion by increasing the effective absorptive area and improving the nutrient transport system (Awad et al., 2009). The increase of villus length of different segments of the intestine (duodenum and caecum), as the authors measured, may be attributed to the role of the intestinal epithelium, as a natural barrier against pathogenic bacteria and toxic substances that are present in the intestinal lumen. Pathogens and toxic substances cause disturbances in the normal microflora and in the intestinal epithelium that could alter the permeability of this natural barrier, facilitating the invasion of pathogens and modifying the metabolism, so leading to chronic inflammatory processes at the intestinal mucosa (Khan, 2013). Organic acid salts reduced the growth of many pathogenic intestinal bacteria. Consequently, MCFAs reduced intestinal colonization and the infectious process, decreased the inflammatory process at the intestinal mucosa, and this improved villus length and function of secretion, digestion and absorption of nutrients (Khan \& Iqbal, 2016; Khan et al., 2016).

MCFA supplementation did not affect serum HDL-cholesterol level, while serum triglyceride concentration was significantly increased in treatment groups of broilers. Contrary to these results, Cater et al. (1997) demonstrated HDL-cholesterol reductions in human beings on diets rich in MCFAs or oleic acid.

The triglyceride-increasing effect of MCFAs observed in the present study is supported by the results of Hill et al. (1990). However, the effects of MCFAs on triglyceride and cholesterol seemed to be contradictory, since triglyceride and cholesterol secretion are regulated in a coordinated manner (Marten et al., 2006). One possible explanation could be that higher MCFAs stimulated insulin secretion and promoted anabolic-related processes (Hill et al., 1990). Thus, increased de novo fatty acid synthesis would lead to an increase in triglyceride production (Hill et al., 1990).

The low counts of LAB, Enterococcus spp., S. aureus and E. coli that were determined in the ileum might be explained by MCFAs being incorporated into bacterial cell membranes or entering bacterial cells in undissociated form and so negatively influencing the bacterial metabolism (Desbois \& Smith, 2010; Zeitz et al., 2015). Besides reduction of gram-positive and gram-negative pathogens, dietary fatty acids might inhibit beneficial bacteria such as Lactobacillus (Van der Hoeven-Hangoor et al., 2013), which was shown in the present study. On the other hand, lower counts of these bacteria in the duodenum of the control broilers might be due to the larger influence of dietary MCFAs in those parts of the gastrointestine that are crucial to nutrient absorption (jejunum and ileum) (Zeitz et al., 2015). The lowest LAB count, which was found in the caecum of the E-II broilers, could be because coccidiostat, beside direct suppression of coccidia, was observed to suppress the major groups of gram-positive bacteria such as LAB and C. perfringens, thus facilitating the hosts' direct competition for nutrients (Józefiak et al., 2013). Coccidiostat also decreased the microbial deconjugation of bile salts, thus improving fat digestibility, growth and feed utilization in birds (Józefiak et al., 2013). The E-I group broilers had lower LAB count than the control broilers, which demonstrates that dietary MCFAs modulated the microbial ecology of the broiler gastrointestinal tract in a manner similar to coccidiostat. Higher LAB count in caecum of broilers fed dietary phytobiotic could also be due to formation of soaps with $\mathrm{Ca}$, which reduce antimicrobial properties (Zeitz et al., 2015).

\section{Conclusion}

Dietary MCFA supplementation should be considered an alternative non-antibiotic feed additive (growth promoter). The beneficial effect of dietary MCFAs, which are reflected through the better production results and improved microbiological status of broilers, can be attributed to the effects that MCFAs have on the digestive tract, preserving its integrity, improving morphometric parameters, and changing the intestinal microflora. 


\section{Acknowledgements}

This article was supported by the Ministry of Education, Science and Technological Development of the Republic of Serbia via the project 'Selected Biological Hazards to the Safety/Quality of Food of Animal Origin and the Control Measures from Farm to Consumer' (31034).

\section{Authors' Contributions}

BB and RM participated in its design and coordination and participated in drafting of the manuscript. AR carried out histomorphological examination. DŠ performed production performance and VĐ. performed fatty acids analysis. MŽB and $\mathrm{J} \boxminus$ conceived of the study (carcass cuts), and MG conceived of the serum biochemistry analysis. JC and BM performed statistical examination. All authors read and approved the final manuscript.

\section{Conflict of Interest Declaration}

The authors declare that they have no conflicts of interest.

\section{References}

Abudabos, A.M., Alyemni, A.H., Dafalla, Y.M. \& Khan, R.U., 2017. Effect of organic acid blend and Bacillus subtilis alone or in combination on growth traits, blood biochemical and antioxidant status in broiler exposed to Salmonella typhimurium challenge during the starter phase. J. Appl. Anim. Res. 45, 538-542.

Adil, S.B., Banday, T., Bhat, G.A., Mir, M.S. \& Rehman, M., 2010. Effect of dietary supplementation of organic acids on performance, intestinal histomorphology, and serum biochemistry of broiler chicken. Vet. Med. Int. 1-7. http,//dx.doi.org/10.4061/2010/479485.

Applegate, T.J., Klose, V., Steiner, T., Ganner, A. \& Schatzmayr, G., 2010. Probiotics and phytogenics for poultry, Myth or reality? J. Appl. Poult. Res. 19, 194-210. https,//doi.org/10.3382/japr.2010-00168

Awad, W.A., Chareeb, K., Abdel-Raheem, S., Böhm, J., 2009. Effects of dietary inclusion of probiotic and symbiotic on growth performance, organ weight and intestinal histomorphology of broiler chickens. Poult. Sci. 88, 49-56. https,//doi.org/10.3382/ps.2008-00244

Baltić, Z.M., Marković, R. \& Đorđević, V., 2011. Nutrition and meat quality. Tehnologija Mesa 52,154-159.

Baltic, T., Baltic, Z.M., Misic, D., Ivanovic, J., Janjic, J., Boskovic, M. \& Dokmanovic, M., 2015. Influence of marination on Salmonella spp. Growth in broiler breast fillets. Acta. Vet. (Beogr). 65, 417-428. doi,10.1515/acve-2015-0034

Bansal, G.R., Singh, V.P. \& Sachan, N., 2011. Effect of probiotic supplementation on performance of broilers. Asian J. Anim. Sci. 5, 277-284.

Bergamo, P., Palmieri, G., Cocca, E., Ferrandino, I., Gogliettino, M., Monaco, A., Maurano, F. \& Rossi, M., 2016. Adaptive response activated by dietary cis9, trans11 conjugated linoleic acid prevents distinct signs of gliadininduced enteropathy in mice. Eur. J. Nutr. 55, 729-740. doi, 10.1007/s00394-015-0893-2

Bruggeman, G., 2002. Evaluation of the effect of alternatives for growth promoters against Salmonella infection in pigs. PhD dissertation. Univ. Ghent, Belgium.

Cater, N.B., Heller, H.J. \& Denke, M.A., 1997. Comparison of the effects of medium-chain triacylglycerols, palm oil, and high oleic acid sunflower oil on plasma triacylglycerol fatty acids and lipid and lipoprotein concentrations in humans. Am. J. Clin. Nutr. 65, 41-45.

de Los Santos, F.S., Donoghue, A.M., Venkitanarayanan, K., Dirain, M.L., Reyes-Herrera, I., Blore, P.J. \& Donoghue, D.J., 2008. Caprylic acid supplemented in feed reduces enteric Campylobacter jejuni colonization in ten-day-old broiler chickens. Poult. Sci. 87, 800-804. https,//doi.org/10.3382/ps.2007-00280

Desbois, A.P. \& Smith, V.J., 2010. Antibacterial free fatty acids, Activities, mechanisms of action and biotechnological potential. Appl. Microbiol. Biotechnol. 85, 1629-1642. doi, 10.1007/s00253-009-2355-3

Dove, C.R, 1993. The effect of adding copper and various fat sources to the diets of weanling swine on growth performance and serum fatty acid profiles. J. Anim. Sci. 71, 2187-2192.

Furuse, M., Mabayo, R.T., Kita, K. \& Okumura, J., 1992. Effect of dietary medium chain triglyceride on protein and energy utilization in growing chicks. Br. Poult. Sci. 33, 49-57. https,//doi.org/10.1080/00071669208417443

Garciá, V., Catalá-Gregori, P., Hernandez, F., Megiás, M.D. \& Madrid, J., 2007. Effect of formic acid and plant extracts on growth, nutrient digestibility, intestine mucosa morphology, and meat yield of broilers. J. Appl. Poult. Res. 16, 555-562. https,//doi.org/10.3382/japr.2006-00116

Glamočlija, N., Starčević, M., Ivanović, J. Janjić, J., Bošković, M., Đorđević, J., Marković, R. \& Baltić, M.Z., 2016. Comparative analysis of meat chemical composition of different broiler provenances. Meat Technol. 57, 1-5.

Gunal, M, Yayli, G., Kaya, O., Karahan, N. \& Sulak, O., 2006. The effects of antibiotic growth promoter, probiotic or organic acids supplementation on performance, intestinal microflora and tissue of broilers. Int. J. Poult. Sci. 5, 149-155.

Gutierrez Del Alamo, A., De Los Mozos, J., Van Dam, T.P. \& De Ayala, P.P., 2006. The use of short and medium chain fatty acids as an alternative to antibiotic promoters in broilers infected with malabsorption syndrome. In: Proc. 16th European Sym. Poult. Nutr., Strasbourg, France. pp. 317-320.

Hayat, T., Sultan, A., Khan, R.U., Khan, S., Zahoor ul Hassan, Ullah, R. \& Aziz, T., 2014. Impact of organic acid on some liver and kidney function tests in japanese Quails, Coturnix coturnix japonica. Pak. J. Zool. 46, 1179-1182.

Hermans, D., Van Deun, K., Messens, W., Martel, A., Van Immerseel, F. Haesebrouck, F., Rasschaert, G, Heyndrickx, M. \& Pasmans, F., 2011. Campylobacter control in poultry by current intervention measures ineffective, Urgent need for intensified fundamental research. Vet. Microbiol. 52, 219-228. doi, 10.1016/j.vetmic.2011.03.010

Hill, J.O., Peters, J.C., Swift, L.L., Yang, D., Sharp, T., Abumrad, N. \& Greene, H.L., 1990. Changes in blood lipids during six days of overfeeding with medium or long chain triglycerides. J. Lipid. Res. 31, 407-416. 
https,//doi.org/10.1017/S1466252311000089

Isaac, D., Deschepper, K., Vanmeenen, E. \& Maertens, L., 2013. The effect of a balanced mixture of medium chain fatty acids on zootechnical performance in broilers. In: Proc. 24th Ann. Aust. Poult. Sci. Sym., Sydney. pp. 196-199.

Janjić, J., Katić, V., Ivanović, J., Bošković, M., Dokmanović, M., Baltić, T. \& Baltić, M., 2016. Temperatures, cleanliness and food storage practices in domestic refrigerators. Int. J. Consum. Stud. 40, 276-282. doi, 10.1111/ijcs.12252

Józefiak, D., Kierończyk, B., Juśkiewicz, J., Zduńczyk, Z., Rawski, M., Długosz, J., Sipp, A. \& Højberg, O., 2013. Dietary nisin modulates the gastrointestinal microbial ecology and enhances growth performance of the broiler chickens. PLoS ONE 8 (12), 85347. https,//doi.org/10.1371/journal.pone.0085347

Kabara, J.J. \& Marshal, D.L., 2005. Medium-chain fatty acids and esters. In: Antimicrobials in Food. CRC Press, Boca Raton, FL. pp. 327-360.

Khan, R.U., Chand, N. \& Ali, A., 2016. Effect of organic acids on the performance of Japanese quails. Pak. J. Zool. 48, 1799-1803.

Khan, S.H., 2013. Probiotic microorganisms-identification, metabolic and physiological impact on poultry. Wrlds Poult. Sci. J. 69, 601-612. https,//doi.org/10.1017/S0043933913000603

Khan, S.H. \& Iqbal, J., 2016. Recent advances in the role of organic acids in poultry nutrition. J. Appl. Anim. Res. 44 359-369. https,//doi.org/10.1080/09712119.2015.1079527

Khosravinia, H., 2015. Effect of dietary supplementation of medium-chain fatty acids on growth performance and prevalence of carcass defects in broiler chickens raised in different stocking densities. J. Appl. Poult. Res. 24, 1-9. http,//dx.doi.org/10.3382/japr/pfu001

Kum, S., Eren, U., Onol, A. \& Sandikci, M., 2010. Effects of dietary organic acid supplementation on the intestinal mucosa in broilers. Rev. Med. Vet. 161, 463-468.

Leeson, S., Namkung, H., Antongiovanni, M. \& Lee, E.H., 2005. Effect of butyric acid on the performance and carcass yield of broiler chickens. Poult. Sci. 84, 1418-1422. https,//doi.org/10.1093/ps/84.9.1418

Marten, B., Pfeuffer, M. \& Schrezenmeir, J., 2006. Medium-chain triglycerides. Int. Dairy. J. 16, $1374-1382$. https,//doi.org/10.1016/j.idairyj.2006.06.015

Miller, D., Johnston, Z., Mullan, B., Pluske, J. \& Hansen, C., 2009. Nutritional manipulation of the somatotropic axis in grower and finisher pigs. Report prepared for the Co-operative Research Centre for an Internationally Competitive Pork Industry. December. 2009. Australia. pp. 1-12.

Mountzouris, K.C., Tsitrsikos, P., Palamidi, I., Arvaniti, A., Mohnl, M., Schatzmayr, G. \& Fegeros, K., 2010. Effect of probiotic inclusion levels in broiler nutrition on growth performance, nutrient digestibility, plasma immunoglobulins, and cecal microflora composition. Poult. Sci. 89, 58-67. https,//doi.org/10.3382/ps.2009-00308

Newell, D.G. \& Wagenaar, J.A., 2000. Poultry infections and their control at farm level. In: I. Nachamkin \& M.J. Blaser (ed). Campylobacter. 2nd edition. ASM Press, Washington, DC. pp. 497-509.

O'Dea, E.E., Fasenko, G.M., Allison, G.E., Korver, D.R., Tannock, G.W. \& Guan, L.L., 2006. Investigating the effects of commercial probiotics on broiler chick quality and production efficiency. Poult. Sci. 85, 1855-1863. https,//doi.org/10.1093/ps/85.10.1855

Onderci, M., Sahin, N., Cikim, G., Ydyn, A., Ozercan, I., 2008. a-glucanase-producing bacterial culture improves performance and nutrient utilization and alters gut morphology of broilers fed a barley-based diet. Anim. Feed Sci. Technol. 146, 87-97. https,//doi.org/10.1016/j.anifeedsci.2007.11.005

Panda, A.K., Rama, R., Rao, S.V., Raju, M.V.L.N. \& Shyam, G.S., 2009. Effect of butyric acid on performance, gastrointestinal tract health and carcass characteristics in broiler chickens. Asian-Austral. J. Anim. Sci. 22, 1026-1031.

Rodríguez-Lecompte, J.C., Yitbarek, A., Brady, J., Sharif, S., Cavanagh, M.D., Crow, G., Guenter, W.J., House, D. \& Camelo-Jaimes, G., 2012. The effect of microbial nutrient interaction on the immune system of young chicks after early probiotic and organic acid administration. J. Anim. Sci. 90, 2246-2254. doi,10.2527/jas.2011-4184

Saeidi, E., Shokrollahi, B., Karimi, K. \& Amiri-Andi, M., 2016. Effects of medium-chain fatty acids on performance, carcass characteristics, blood biochemical parameters and immune response in Japanese quail. Br. Poult. Sci. 57, 358-363. https,//doi.org/10.1080/00071668.2016.1169508

Shokrollahi, B., Yavari, Z. \& Kordestani, A.H., 2014. Effects of dietary medium-chain fatty acids on performance, carcass characteristics, and some serum parameters of broiler chickens. Br. Poult. Sci. 55, 662-667. https,//doi.org/10.1080/00071668.2014.955836

Skrivanova, E., Marounek, M., Dlouha, G. \& Kanha, J., 2005. Susceptibility of Clostridium perfringens to C2-C18 fatty acids. Lett. Appl. Microbiol. 41, 77-81. doi, 10.1111/j.1472-765X.2005.01709.x

Smirnov, A., Perez, R., Amit-Romach, E., Sklan, D. \& Uni, Z., 2005. Mucin dynamics and microbial populations in the chicken small intestine are changed by dietary probiotic and antibiotic growth promoter supplements. J. Nutr. 135, 187-192.

Sultan, A., Ullah, T., Khan, S. \& Khan, R.U., 2015. Effect of organic acid supplementation on the performance and ileal microflora of broiler during finishing period. Pak. J. Zool. 47(3), 635-639.

Tan, G.H. \& Long, K., 2012. Preliminary study of anticoccidial activity of medium chain fatty acids (MCFA) and their corresponding monoglycerides on broiler chicken coccidiosis. Int. J. Biotechnol. Wellness Ind 1, $134-141$. doi,http,//dx.doi.org/10.6000/1927-3037/2012.01.02.05

Tellez, G., Higgins, S.E., Donoghue, A.M. \& Hargis, B.M., 2006. Digestive physiology and the role of microorganisms. J. Appl. Poult. Res. 15, 136-144. https,//doi.org/10.1093/japr/15.1.136

Timmerman, H.M., Veldman, A., Van den Elsen, E., Rombouts, F.M. \& Beynen, A.C., 2006. Mortality and growth performance of broilers given drinking water supplemented with chicken-specific probiotics. Poult. Sci. 85, 1383-1388. https,//doi.org/10.1093/ps/85.8.1383 
Trbovic, D., Vranic, D., Djinovic-Stojanovic, J., Petronijevic, R., Milijasevic, M., Matekalo-Sverak, V. \& Spiric, A., 2011. Fatty acid profile of carp fish species from two aquaculture systems. Proc. 5th International Conference Aquaculture and Fishery, June. 1-3, Belgrade, Serbia. pp. 80-84.

Van der Hoeven-Hangoor, E., Van der Vossen, J.M.B.M., Schuren, F.H., Verstegen, M.A., De Oliveira, J.E., Montjin, R.C. \& Hendriks, W.H., 2013. Ileal microbiota composition of broilers fed various commercial diet compositions. Poult. Sci. 92, 2713-2723. https,//doi.org/10.3382/ps.2013-03017

Van Immerseel, F., De Buck, J., Boyen, F., Bohez, L., Pasmans, F., Volf, J., Sevcik, M., Rychlik, I., Haesebrouck, F. \& Ducatelle, R., 2004. Medium-chain fatty acids decrease colonization and invasion through hilA suppression shortly after infection of chickens with Salmonella enterica serovar Enteritidis. Appl. Environ. Microbiol. 70, 3582-3587. doi,10.1128/AEM.70.6.3582-3587.2004

Vieira, S.L., Oyarzabal, O.A., Freitas, D.M., Berres, J., Peña, J.E.M., Torres, C.A. \& Coneglian, L., 2008. Performance of broilers fed diets supplemented with sanguinarine-like alkaloids and organic acids. J. Appl. Poult. Res. 17, 128-133. https,//doi.org/10.3382/japr.2007-00054

Wang, J., Wang, X., Li, J., Chen, Y., Yang, W. \& Zhang, L., 2015. Effects of dietary coconut oil as a medium-chain fatty acid source on performance, carcass composition and serum lipids in male broilers. Asian-Austral. J. Anim. Sci. 28, 223-230. doi,10.5713/ajas.14.0328

Yamabayashi, S., 1987. Periodic acid-Schiff-Alcian Blue. A method for the differential staining for glycoproteins. Histochem. J. 19, 565-571. https,//doi.org/10.1007/BF01687364

Zeitz, J.O., Fennhoff, J., Kluge, H., Stangl, G. I. \& Eder, K., 2015. Effects of dietary fats rich in lauric and myristic acid on performance, intestinal morphology, gut microbes, and meat quality in broilers. Poult. Sci. 94, $2404-2413$. https,//doi.org/10.3382/ps/pev191

Zentek, J., Buchheit-Renko, S., Ferrara, F., Vahjen, W., Van Kessel, A.G. \& Pieper, R., 2011. Nutritional and physiological role of medium-chain triglycerides and medium-chain fatty acids in piglets. Anim. Health. Res. Rev. 12, 83-93. 